\title{
Políticas de conciliación: ajustándolas a la vida cotidiana
}

Katherina Kuschel ${ }^{1}$ e Lupicinio Íñigue $z^{2}$

Departamento de Psicología Social de la Universidad Autónoma de Barcelona

\begin{abstract}
A partir de un enfoque socio-técnico y una perspectiva de género, nos hemos planteado mostrar la relación que existe entre el usuario, en este caso, el Personal Docente e Investigador y las políticas de conciliación trabajo-familia que ofrece la Universitat Autònoma de Barcelona, en Bellaterra. Veremos las estrategias de traducción de estos instrumentos de conciliación que son reflejadas a través de la forma en que se completan los procesos de domesticación. Descubriremos que las capacidades de las tecnologías no están nunca dadas per se, sino que aprehender sus usos pasa siempre por un trabajo de interpretación; traducción que en este caso tiene relación con una cultura sexista y jerárquica de la organización.
\end{abstract}

Palabras clave: Conciliación trabajo y familia, Domesticación, Traducción, Sexismo benevolente.

Work-life balance policies: adjusting them into everyday life

Starting with a social-construction-of-technology (SCOT) approach and a gender perspective, we have considered to show the relation that exists between the user, in this case, the Professors and the work-life balance policies, that Universitat Autònoma of Barcelona offers, in Bellaterra. We will see the translation strategies of these instruments of conciliation, that are reflected across the way in which the domestication processes are completed. We will discover that the technologies capacities are never given per se, but to hold its uses always goes through a work of interpretation; translation that in this case is related to a sexist and hierarchic organizational culture.

Keywords: Work Life Balance, Domestication, Translation, Benevolent Sexism.

\section{Introducción}

L a vida cotidiana es definida por Lefebvre (1971) "como un set de funciones que conectan y reúnen sistemas que podrían parecer diferentes". Muchos artefactos tecnológicos están directamente relacionados con la vida cotidiana. Inmediatamente podemos pensar en el coche, los electrodomésticos, los móviles, el televisor, etc. Algunos estudios de ciencia, tecnología y sociedad (también llamados CTS) se han inspirado en dar sentido a las modernas tecnologías y mostrar su rol en la vida cotidiana, además de observar a través de la ventana de la tecnología el cambio cultural y la estabilidad.

Sin embargo, las políticas de conciliación entre la vida laboral y familiar/personal parecieran no ser muy parte del día a día. Las mujeres, y cada vez más comúnmente, los hombres, se toman bajas o permisos cuando nace un hijo. No se tiene hijos cada día, ni los hijos requieren de nuestros cuidados para toda la vida. Pero sí podemos pensar que la toma de estos instrumentos de equilibrio trabajo y familia podrían tener un impacto cotidiano y rutinario, en la medida que los usuarios se los apropian. El objetivo general de este trabajo es mostrar la relación que existe entre el usuario, en este caso, el personal docente e investigador (en

1 Becaria de la Fundación Carolina.Estudios de Doctorado en Psicología Social, Departamento de Psicología Social, Universidad Autónoma de Barcelona.

2 Catedrático de Psicología Social, Departamento de Psicología Social, Universidad Autónoma de Barcelona:

http://psicologiasocial.uab.es/lupicinio/ 
adelante, PDI) y las políticas de conciliación trabajo-familia que ofrece la Universitat Autònoma de Barcelona, en Bellaterra (en adelante, UAB). Basándonos en la perspectiva socio-técnica y el sexismo benevolente, analizaremos a lo largo del artículo la forma en que las políticas son domesticadas e integradas rutinariamente a la vida cotidiana. Veremos los procesos de des-domesticación y re-domesticación y notaremos cómo estos procesos se ven condicionados o traducidos por una cultura sexista y jerárquica.

Los participantes del estudio han sido profesores de la UAB que fueron entrevistados durante la primavera de 2007. El PDI puede clasificarse como usuario intermediario o semifinal de las políticas o programas organizados por la Universitat Autònoma de Barcelona. Los usuarios finales pueden ser ellos mismos o sus familias, quienes son los que disfrutan las consecuencias de este proceso, la nueva disposición de tiempo del PDI. Para este estudio, seguiremos el hilo centrándonos específicamente en recursos tales como la baja por maternidad, el permiso por paternidad, la jornada reducida y el servicio de guardería Gespa, todos ellos instrumentos que persiguen ayudar a equilibrar los tiempos destinados al trabajo y la familia de los empleados.

En primer lugar presentaremos las perspectivas teóricas desde las cuales observamos las políticas de conciliación trabajo-familia: la perspectiva socio-técnica y complementamos la visión con el concepto de sexismo ambivalente. En segundo lugar, analizaremos bajo esa óptica algunas estrategias de traducción y procesos de domesticación de los profesores participantes de esta universidad. Este trabajo plantea una nueva forma de entender las políticas de conciliación como una tecnología que es apropiada y domesticada por los usuarios.

\section{Perspectiva socio-técnica}

Los sociólogos franceses Michel Callon, Bruno Latour y el británico John Law han contribuido a conformar una perspectiva socio-técnica en ciencias sociales, un enfoque que plantea la tecnología como facilitador para conocer los cambios sociales, propusieron la teoría actor-red (en adelante ANT, por sus siglas en inglés), una teoría del método o más bien el método mismo (Latour, 2005, p. 142). Ella se denomina "teoría" sin serlo exactamente, más bien es una caja de herramientas para pensar los procesos de transformación social. Este enfoque de método material (humanos y no humanos) y semiótico (conceptos) se distingue de la teoría social convencional al hacer énfasis en redes y enlaces más que en héroes individuales, quienes pueden ser humanos o no humanos, sin embargo, todos hacen algún trabajo para mantener la red.

Así entonces, Callon propone la construcción de un cuadro común y general para interpretar el carácter incierto de la naturaleza y sociedad llamado principio de simetría generalizada (Callon, 1986, pp. 176-177). Con el principio de simetría generalizada no sólo se tratará de la misma manera a la verdad y al error, a los vencedores y a los vencidos de la historia de las ciencias, sino igualmente a la sociedad y a la naturaleza, a los humanos y a los no humanos. Además del principio de simetría generalizada, Callon parte de otros dos principios para esta nueva manera de observar: el agnosticismo (agnosticism) que se refiere a la imparcialidad entre los actores comprometidos en la controversia, y la libre asociación (free association) o el abandono de toda distinción previa entre lo natural y lo social.

Una de las declaraciones de ANT es abandonar las categorizaciones a priori, romper con las clasificaciones y guardar cada elemento en pequeños frascos, sino simplemente seguir el enlace que une a estos elementos (Latour, 2005, p. 141). De esta forma, se pretende también mantener la ambigüedad y la ambivalencia en la relación entre estos elementos heterogéneos (Lie \& Sorensen, 1996, p. 12). 
Mientras los actores son entendidos normalmente como seres conscientes (y también para este trabajo), los actantes se constituyen de todo tipo de figuras autónomas que componen nuestro mundo. Actante puede ser cualquier cosa que esté dotado de agencia, incluyendo personas o grupos de personas y objetos materiales; leyes, políticas, declaraciones, inscripciones, guiones, instrucciones, manuales, estadísticas (cualquier texto), artefactos técnicos (móviles, ordenadores, etc.), objetos de estudio, conceptos, organizaciones, profesiones, habilidades, dinero, etc.

Ningún actante es tan débil como para no poder reclutar a otro. Entonces ambos se reúnen y se transforman en un tercer actante, el cual puede por eso moverse más fácilmente. Un remolino es formado, y crece al transformarse en muchos otros (Latour, 1988, p. 159).

Como resultado, emergen actores-red heterogéneos; en ellos cada actante está conectado, es dependiente, influyente y fortalecedor de todos los demás. Un actor-red son asociaciones de muchos actores y actantes. Las relaciones traducen, median, transforman continuamente y crean nuevas relaciones. Y por lo tanto, se crean nuevas entidades derivadas de esas relaciones. "Un actor-red es simultáneamente un actor cuya actividad está estableciendo contactos con elementos heterogéneos y una red que es capaz de redefinir y transformar a lo que la compone" (Callon, 1987, p. 93).

Es central para ANT (a veces también conocida como sociología de la traducción) el concepto de traducción: "Posiblemente hablar de traducción es uno de los modos más interesantes actualmente de evitar hacer inteligibles las dinámicas entre entidades en términos de representación o de reflejo de algo preexistente" (Vitores, 2001). Callon (1986) desarrolló ampliamente el término aludiendo a un estudio de cómo los biólogos marinos de la Bahía de Saint-Brieuc intentaron reponer la población de vieiras. Derivado de esta investigación, Michel Callon definió cuatro momentos de traducción; a) problematización: ¿Cuál es el problema y qué necesita para resolverse? ¿Quiénes son los actores relevantes? En este ejemplo fueron identificados cuatro actores: los pescadores preocupados por la disminución en la extracción, las vieiras, preocupadas por morir, los colegas científicos, y los tres investigadores, quienes estaban interesados en instaurarse a sí mismos como punto de paso obligado (OPP, por sus siglas en inglés) y hacerse indispensables para los demás actores involucrados, creando una preocupación común, icómo podemos anexar las vieiras a los dispositivos de cultivo creados para ellas?; b) el "interesamiento", que consiste en tener a los actores interesados y negociar con ellos los términos de su implicación en el caso; c) el reclutamiento es la aceptación de los actores a seguir los acuerdos definidos durante el proceso de interesamiento; y d) la movilización de los aliados es delegar en los demás actores las acciones que se han planteado los investigadores. Sin embargo, esta definición esquemática de traducción es sólo una de las muchas maneras en que se puede traducir. Más adelante, conoceremos los procesos de domesticación como una forma especial de traducción.

\section{Políticas de conciliación como tecnología}

En primer lugar, es pertinente definir las políticas de conciliación: también son conocidas como "familiarmente responsables" (término acuñado por IESE Business School) y comprenden:

flexibilidad de los horarios laborales (horario adaptable, trabajo parcial, etc.); excedencias (para cubrir las necesidades de la familia de los empleados o para ampliar su formación); flexibilidad en el lugar de trabajo (trabajar desde casa, videoconferencias, etc.); ayudas a la 
conciliación entre la vida familiar y la laboral de los empleados fuera de la empresa (asunción de los gastos o información de guarderías infantiles y centros de día para la atención de los ascendientes que conviven con la familia, inscripciones en gimnasios, etc.); adaptación del trabajo (modificación temporal de tareas y responsabilidades, y rotación del trabajo); cursos dedicados a evitar el estrés (administración del tiempo, preparación del parto y paternidad, gestión del estrés, resolución de conflictos, etc.), y otros tipos de beneficios (seguros, planes de pensiones, coche de la empresa, etc.).

Los factores que impulsan los programas de conciliación son generalmente el tamaño de la empresa, el porcentaje de empleadas mujeres, la competitividad del mercado laboral y el grado de preocupación por reclutar y retener personal. Estas políticas podrían ser consideradas como tecnologías.

En efecto, si seguimos a Bruno Latour (2002), la tecnología debe ser entendida antes como adjetivo que como sustantivo, pues es un modo de relacionarse calificado como pliegue. Es ese trabajo de plegar articulaciones y aunar elementos heterogéneos - tiempos, espacio y agentes ontológicamente diferentes - lo que define a la tecnología. Un ejemplo que ilustra esto es un "artículo publicado". Este es el resultado de revistas, autores, citas, corrientes o tradiciones de pensamiento, imprentas, universidades, entre otros. El artículo es el pliegue mismo que pone en relación estos elementos y los define.

Las políticas escritas como textos poseen cualidades inherentes tales como mensajes ideológicos, que se trasportan y terminan inadvertidamente absorbidos por un público receptor, o si este público puede participar en la construcción del significado de esos textos porque, en realidad, no está predeterminado en los contenidos (Hine, 2000, p. 50). Para las políticas de conciliación trabajo y familia, este mensaje tiene que ver con la igualdad, paridad y justicia. Últimamente ha venido surgiendo una interesante aproximación a este respecto, que indica que la producción de un texto mediático traza una relación con la audiencia y que el público puede seguir, reinterpretar, o rechazar tal relación. El resultado, alineado con la perspectiva constructivista de la tecnología, nos invita a centrar nuestra atención en los procesos sociales a través de los cuales los textos mediáticos se producen y consumen.

En otras palabras, si tomásemos las tecnologías como texto, podríamos leer de sus manuales e instrucciones, el guión y notaríamos que estos textos podrían poseer un significado intrínseco, y eso tiene efectos o una interpretación particular para los lectores o usuarios, en cambio puede pensarse también que los significados florecen desde el posicionamiento que subyace en el lector, y que el texto no tendría relación con la interpretación.

Para ello, Keith Grint y Steve Woolgar (1997) emplean la metáfora de la tecnología como texto: por un lado, el proceso de diseño pasa por manos de creadores que se basan en sus propias nociones acerca de aquello que los usuarios tendrían que hacer delante del artefacto técnico; por otro lado, el consumo de la tecnología pasa por una serie de procesos de negociación e interpretación. Las personas "leen" el texto de la tecnología, sujetas a las relaciones configuradas con sus productores, y también con la misma tecnología. Su lectura errática es ciertamente posible siempre que un usuario esté "mal configurado". La metáfora de la tecnología como texto centra su atención en la contingencia de las prácticas a través de las cuales las políticas de conciliación adquieren sentido, tanto en términos de su producción (creación y redacción) como de su uso, que serán parte del mismo proceso. La investigadora escoge la perspectiva socio-técnica y en especial la metáfora de las tecnologías como textos para poder leer en las acciones que provocan las políticas de conciliación; un cambio social o una estabilidad. La ventaja de esta forma de ver las políticas es poder reflejar en ellas acción y producción de percepciones, espacios y nuevas formas de entender conceptos cotidianos como la familia y el trabajo, manteniendo un enfoque relacional y no aislado de cada elemento.

Para seguir el hilo de este estudio, es muy importante que las políticas de conciliación sean leídas en clave de tecnologías, asumiendo que éstas pueden ser leídas como textos, y que 
tanto humanos como no-humanos tienen agencia. De esta forma podemos entender a estas políticas de conciliación como un artefacto que guía hacia la acción, y de una determinada forma, que eventualmente podrá ser domesticada según los usuarios vayan paulatinamente apropiándose de las políticas como un recurso. Es por esto, que a partir de aquí, las políticas de conciliación serán entendidas como actantes, relacionadas a su vez con muchos otros actores y actantes: los profesores, el departamento, intranet, los convenios colectivos, las leyes, las normativas internas de la universidad, los portavoces, los usuarios, entre otros.

\section{Sexismo ambivalente}

Durante finales del siglo XX, se produjeron cambios significativos en el paradigma de producción que caracterizó al capitalismo industrial, transformando así los patrones del empleo. A su vez, las mujeres emergieron en el escenario público, presionando para ingresar masivamente al mercado de trabajo y conquistar posiciones de igualdad con los varones en los espacios económicos, sociales y políticos. En una sociedad acostumbrada a ver a las mujeres en las tareas domésticas y familiares, exclusivamente, estos procesos han generado profundas tensiones en las formas de conciliar el trabajo y la familia, las que se habían consolidado durante el siglo pasado. Hoy día se hace necesaria una reflexión que permita dar respuestas y diseñar políticas públicas que favorezcan la conciliación entre trabajo y familia, entre los espacios público y privado, que no reproduzcan la discriminación laboral, las desigualdades de género y que posibiliten la vida familiar.

Para ver cómo los procesos de domesticación son influidos por una perspectiva de género, simplificaremos y nos remitiremos, para este caso, sólo al concepto del sexismo ambivalente. Tanto las recientes teorías como el trabajo empírico cuestionan la concepción tradicional de que el sexismo consiste en una simple antipatía hacia las mujeres, en extremos, también llamada "misoginia". Según Glick y Fiske (1996), esta conceptualización tradicional del prejuicio como un reflejo de la hostilidad hacia las mujeres olvida los sentimientos positivos que existen hacia ellas y que coexisten con la antipatía sexista. Según estos autores, el sexismo ambivalente está formado por dos componentes claramente diferenciados (aunque relacionados): el sexismo hostil (SH) y el sexismo benévolo o benevolente (SB). El primero coincide básicamente con el sexismo concebido tradicionalmente: una actitud negativa hacia las mujeres. El sexismo benévolo es definido como un conjunto de actitudes interrelacionadas hacia las mujeres que son sexistas en cuanto las considera de forma estereotipada y limitadas a ciertos roles, pero que tiene un tono afectivo positivo (para el perceptor).

La teoría del sexismo ambivalente señala que las actitudes y comportamientos sexistas refuerzan el dominio masculino, impidiendo a las mujeres ser autosuficientes. A pesar de las demandas de equidad de género, el sexismo, lejos de desaparecer, adquiere formas más sutiles, pero igualmente perjudiciales.

Tanto el sexismo benévolo como el hostil tienen sus raíces en las condiciones sociales (según el sistema sexo-género) de múltiples sociedades donde, mayoritariamente y desde hace ya muchísimo tiempo, han sido los varones quienes lideran las instituciones económicas, legales y políticas. La dominación de los varones favorece el $\mathrm{SH}$, dado que los grupos dominantes inevitablemente promueven estereotipos sobre su propia superioridad. Pero la dependencia de los varones favorece el SB: esta dependencia les lleva a reconocer que las mujeres son un recurso valioso que hay que proteger y que hay que ofrecer afecto a aquellas mujeres que satisfacen sus necesidades. 


\section{Estrategias de traducción}

En la UAB, las políticas de conciliación trabajo-familia llevan implementándose hace 5 años. Algunos afirman la importancia de que estas políticas de conciliación trabajo-familia sean reflejo del espíritu de la UAB en términos de acciones por la igualdad:

si sólo fabricamos conciliación para las mujeres reforzamos la división sexual del trabajo, es decir, no rompemos aquello que hace que las mujeres estén peor situadas en el mundo de lo público. [P1: marzo 2007].

las políticas de conciliación que salen de la Unión Europea son políticas de estrategias laborales, es decir, estrategias para promocionar el empleo femenino, es eso, no son políticas familiares [P1: marzo 2007]

Así, aparentemente existe un fin encubierto en estas políticas, que algunos denuncian que son políticas laborales, y eso es algo que no les gusta decir. Hoy se confunden entre las políticas de conciliación familiares y políticas de igualdad. Las políticas de conciliación no son necesariamente políticas de igualdad, porque no promueven igualdad, a no ser que se obligue a los padres a tomarse los permisos por paternidad, como lo hacen algunos países nórdicos.

\section{El desarrollo de la conciliación en España}

El impulsor de estas políticas es múltiple, al igual que la figura tradicional del "productor". En el sector público, las políticas de conciliación se "cocinan" primero en el ámbito europeo, luego se regulan estatalmente en España, después se adaptan a cada Comunidad Autónoma, y finalmente son incluidas en los municipios en el ámbito local. Así, inspirado en las directivas de la Unión Europea, principalmente en materia laboral, España ha regulado los recursos de conciliación en la Ley 39/1999, hasta estar al nivel de la normativa internacional y comunitaria. Esta ley afecta la negociación colectiva en el sector empresarial privado, exigiendo unos mínimos recogidos en la ley, sin embargo, esto no va en desmedro de iniciativas vanguardistas de aquellas organizaciones privadas punteras en esta materia. Asimismo, la Ley Orgánica 3/2007 para la igualdad viene a confirmar la importancia de la conciliación como corresponsabilidad con el fin de lograr una igualdad efectiva entre hombres y mujeres. Hoy en día, el impulsor en España es una mezcla entre el Parlamento estatal, el Gobierno regional llamado Generalitat de Catalunya, el directorio de las organizaciones, su área de Recursos Humanos, los empleados, ellos representados por sindicatos, organizaciones no gubernamentales, etc. Sin embargo, pareciera ser que todavía estas políticas no están enfocadas a todo el personal:

(...) normalmente cuando se habla de conciliación y se habla ligado a Recursos Humanos, es porque sólo se tiende a las personas que para la empresa tienen un valor añadido, pero no para el conjunto de la plantilla [P1: marzo 2007].

Hay compañías que ya han entendido que algunas personas tienen un límite y cuestan ser retenidas en la organización. iLlega un momento en que priorizan otras cosas?

(...) hace mucho que saben las empresas, que las personas más jóvenes, bien preparadas, no las convences con más dinero [P1: marzo 2007].

¿Qué es entonces lo que ha hecho que las personas tengan tantas percepciones distintas respecto a una misma tecnología? ¿Qué ha hecho que las entendamos de una manera y no de otra? ¿Quién las ha traducido para nosotros? ¿Quién las traduce para el PDI? 
Traducir es lo que los actores-red hacen. Ellos traducen instrumentos, observaciones, inscripciones, habilidades, e intereses de personas a declaraciones alineadas a argumentos particulares (Callon, 1986). En este proceso son identificados los aliados de un argumento, moldeados y alistados. Traducción son "todas las negociaciones, intrigas, actos de persuasión o violencia, gracias a los cuales un actor consigue la adhesión de otros actores, es decir, procesos por los cuales un actor teje una red. El acto de traducción reorganiza las entidades y sus relaciones, prefigura, configura un entramado, una red" (Domènech \& Tirado, 1998, pp. 27-28). Se asume que hay muchas maneras o procesos de traducción y que no se pueden reducir a un sólo esquema, de hecho, la domesticación; hacer nuestra la tecnología, es un tipo de traducción que se puede dar de maneras muy diversas.

En la UAB, como en el resto de universidades públicas españolas, existen dos tipos de PDI. Un PDI funcionario, que se rige por el Estatuto Básico del Empleado Público; y el PDI laboral, que es el PDI contratado y que se rige por el Convenio Colectivo de su sector, en este caso, el de las universidades públicas catalanas. Para concretar este convenio, se realizan una serie de mesas paritarias de negociación. Estos convenios se pactan cada 3 años, y regulan variados temas relativos a las condiciones de los trabajadores: proceso de selección, sus tramos de sueldo, bonos, beneficios, permisos y licencias, vacaciones, excedencias, jubilación, política de género, entre otros. Allí los representantes sindicales aliados proponen sus ideas de conciliación, potenciándose. Podemos decir, que para el caso de los convenios colectivos, el proceso de diseño y génesis de las condiciones, son abiertamente negociadas entre los siete representantes empresariales de las universidades públicas catalanas del sector y los representantes sindicales de sus trabajadores. Una vez consensuado es redactado y publicado en el Diari Oficial de la Generalitat de Catalunya. La organización pública, y en especial su departamento de personal, recibe las leyes y convenios colectivos recién negociados y publicados.

El departamento de personal se encarga de difundir la información y envía un correo electrónico a cada departamento de Facultad de la UAB, adjuntando la nueva normativa vigente, para así dejar en manos de los directores de departamento la responsabilidad de informar las novedades a los PDI. Entonces, la política ha comenzado su recorrido, desde el nodo de la negociación colectiva, pasando por el área de Recursos Humanos para llegar al puesto de trabajo de los potenciales usuarios (Figura 1). Los usuarios son inexpertos que involucran tecnologías en sus actividades diarias. Las tecnologías afectan potencialmente todas las esferas de la vida, como el trabajo, el hogar y el ocio. Para estos efectos, ignoraremos los nodos anteriores a las mesas paritarias de negociación; el proceso de asesoramiento a los líderes en variados temas, las elecciones de representantes sindicales, las sugerencias de los empleados, etc. El conjunto de los nodos expuestos, y otros más, (Figura 1) conforma el actor-red de la conciliación en las universidades catalanas. Entre cada nodo del actor-red, las políticas son traducidas. Esta vez, nos concentraremos en los usuarios "semi-finales" de estas políticas; el profesorado.

Figura 1:

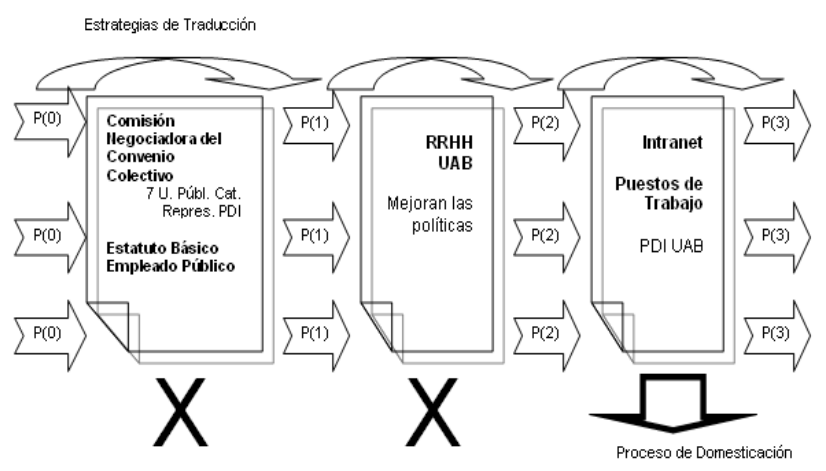




\section{Objetivos, metodología y análisis de datos}

El objetivo general de este trabajo es analizar la incorporación de las políticas de conciliación trabajo y vida personal/familiar a la vida cotidiana de los profesores en la Universitat Autònoma de Barcelona, y para ello, los objetivos específicos son identificar en los distintos procesos de domesticación de los programas de conciliación similitudes y diferencias y analizar estrategias de traducción de las políticas de conciliación para generar una nueva visión sobre el contexto de la producción de ellas.

El estudio se llevó a cabo en una organización de carácter público. La organización escogida es la Universitat Autònoma de Barcelona, en Bellaterra, Cataluña. La muestra contó con diez PDI hombres y mujeres que trabajan a tiempo completo, contratados en tres facultades distintas en la UAB. La técnica utilizada fue la entrevista semi-directiva, con una pauta que reflejaba los objetivos específicos. Además se recogieron las políticas de conciliación procedentes del área de RRHH; sus comunicaciones internas y convenios colectivos y leyes vigentes y aplicables a los PDI (laboral y funcionario) en formato texto o electrónico.

El análisis fue de carácter inductivo que incluye la organización de las ideas principales en unidades de registro. Se crean citas y se relacionan a dichos códigos. Luego de consecutivas revisiones, se crean nuevos códigos que agrupan las ideas según concepto teórico a analizar. Esto último permite que se incorpore ANT y la perspectiva de género, aludiendo al sexismo benevolente.

\section{Proceso de domesticación}

De esta nueva sociología de la tecnología que emergió en los años 80s, y de los cuales se originó ANT, se desprende también la teoría de domesticación (Lie \& Sorensen, 1996). La idea principal es que todos nosotros consumimos tecnología (o artefactos técnicos), integrándola y usándola, y también, cuando gana nuestra atención y nos ha hecho reaccionar ante ella e interesarnos de sus habilidades, funciones y formas. Esta relación dual entre humanos y tecnologías es el resultado del proceso de domesticación. "Domamos" la tecnología en nuestra vida cotidiana. Este proceso se caracteriza por el cambio recíproco; formamos redes con tecnología, en las cuales los significados están atribuidos y las acciones están delegadas a las partes que constituyen esta red. Así, cuando la gente adquiere nuevos artefactos técnicos para integrarlos a sus vidas cotidianas, pasan por un proceso de domesticación. Este proceso de integración implica trabajo tanto para el ámbito práctico como para el simbólico. Cuando las cosas están puestas en uso, rutinas locales son construidas para guiar la aplicación, y las inscripciones generales indican que el proceso podría ser transformado en cualquier momento. Alrededor del proceso de domesticación pueden encontrarse otros dos procesos: el proceso de des-domesticación o despojo, que se inicia cuando el usuario pierde interés en el artefacto porque está gastado o lo quiere reemplazar, y el proceso de re-domesticación en que los usuarios aprenden nuevamente a usar viejas tecnologías para nuevas situaciones o contextos.

Los PDI esperan que haya pasado el período en que trabajaban como ayudantes o becarios y cuando el sueldo era bastante precario. Ahora han superado esto y cuentan con cierta estabilidad laboral y podrían planificar tener hijos. Ahora que los profesores saben que van a tener familia comienzan con la búsqueda de recursos para facilitar la conciliación. No están bien informados. Antes, cuando aún no tenían hijos, esto no se lo planteaban. Sólo al comenzar a pensar en tener hijos el profesorado se cuestiona cómo va a atender al nuevo miembro de su familia. Los PDI saben que al acogerse a los recursos de conciliación hay que 
dejar entrar los cambios que esto supone en la rutina, esto es, acomodarse a las nuevas circunstancias, también llamado proceso de ajuste material (Winance, 2006):

Tendría que dejar mi puesto de coordinadora de promoción de las relaciones externas de la Facultad que es un dinero que gano extra, claro, tendría que dejarlo y pasarlo a alguien, a algún conocido y así decírselo al decano, que yo lo dejo. Y no creo que tuviera ya otros problemas [P3: mayo 2007].

A través de este proceso de ajuste pueden emerger de las personas nuevas percepciones y entendimientos de estos conceptos. Este tipo de profesionales que tienen familia (es uno de los criterios para la selección de los participantes) se plantean preguntas y se problematizan su rol en la familia. A la vez, ponen en una balanza cómo concilian estos dos grandes ámbitos, muchas veces completamente separados uno del otro.

El permiso por paternidad es un recurso relativamente nuevo. Tampoco hay mucho conocimiento, pero a pesar de esto, hay quienes lo consideran ridículo:

Hay gente que lo ve muy bien, y hay gente que en mi caso, encuentra ridículo un hombre con permiso. Si ya lo tiene la mujer, para qué lo va a tener el hombre. Ese es un argumento que lo he oído muchas veces. Argumentos del estilo de "si tu mujer no sabe cambiar pañales" (...) Hay gente que me dijo que no lo hiciera, que no lo pidiera, porque eso daba mala imagen [P10: mayo 2007].

Ellos mismos justifican este comportamiento con una cultura particular atribuida a la institución en la que trabajan, como entorno machista o una cultura jerarquizada:

(...) en el caso de los hombres, hay la sensación aún hoy, de que eso es un poco ridículo. El entorno es machista, aunque nos creamos que no. No es cierto, lo es. Y entonces la sensación de que un hombre pida ese tipo de cosas es extraña, no está bien visto (...) [P10: mayo 2007].

Y eso [la jerarquización] funciona en todos los niveles en la universidad. De cara a fuera, cuando no hay nada en disputa, todos somos iguales, colegas. Pero cuando está en peligro lo que ellos consideran que es su coto privado de caza, entonces alli aparecen todas las jerarquías y lo que haga falta para marcar el territorio [P9: mayo 2007].

Es más, cuando un varón toma este tipo de iniciativas es prácticamente un riesgo si se trata de un pionero en el departamento. Podemos notar las formas en las cuales esta tecnología se ha hecho parte integral de la vida cotidiana, pues va lentamente haciéndose menos y menos presente hasta que por fin, pareciera haber sido suprimida. En conjunto, el set de procesos o ensayos forma un proceso general de la domesticación por el cual un nuevo conocimiento de usuario es creado y el orden moral de la persona es negociado constantemente:

todo el mundo interpretó que yo no iba a utilizar eso para estar más tiempo con mi hijo, sino que lo iba a utilizar para dedicarme más a la investigación. (...) la gente no se acuerda de que tienes una reducción y que te permite hacer eso, sino que ven que llegas más tarde o que sales antes. Eso es lo que se ve [P10: mayo 2007].

El proceso de ajuste emocional (Winance, 2006) se va completando a medida que el PDI conoce las demás posibilidades y así confirma que lo que está haciendo es lo correcto. Para esto tiende a compararse con su cónyuge, sus amistades y colegas del trabajo y hasta con personas que trabajan en la empresa privada y las condiciones que allí se ofrecen. Esto tiene relación con la teorización que ellos mismos hacen para satisfacer el proceso de ajuste emocional.

La que está ganando mucho más que yo, como en el mercado privado, está soltera sin hijos y viviendo en casa de sus padres (...). La empresa privada pagaba bien (...). Ahora hay amigas que sí que están ganando casi el doble que yo, pero también sé que hay amigas que han tenido que 
hacer reducciones de jornada y están ganando mucho menos que yo, teniendo los mismos estudios y formación [P3: mayo 2007].

ella [mi mujer] trabaja en una empresa privada que tiene también sus políticas de conciliación familiar, que le permite tener una reducción de jornada muy buena, trabaja de 9 am a 2:30 pm y mantiene, no la totalidad del sueldo, pero un porcentaje muy importante [P10: mayo 2007].

Otro de los sectores con los que se comparan los PDI habitualmente es con el Personal de Administración y Servicios o PAS. Entienden que PDI y PAS son dos tipos de trabajadores completamente diferentes en la UAB. Los PDI comprenden los problemas en cuanto a la flexibilidad horaria del PAS y sus exigencias laborales, sin embargo, hay un sentimiento de que este entendimiento no es mutuo, por lo tanto pareciera ser que este contraste es bastante negativo:

Aquí los profesores no son lo mismo que el personal administrativo que tiene que fichar [P6: mayo 2007].

(...) hablaban de regular el tema de la conciliación de la vida familiar y laboral y en el mismo sindicato se habla de que eso solamente es importante para el PAS, que en los profesores no es relevante. Porque nosotros tenemos un horario tan flexible. Ves que realmente es flexible pero la gran diferencia es que tú, a las 5 te vas a casa y cierras el chiringuito. No es a las 5pm, sino que a partir de ahora [en verano], desde el primer lunes del mes de junio, [PAS] se van a las 2 de la tarde. Y tú [PDI] sigues haciendo el mismo horario, hasta las 8 de la noche. Es cierto que puedes medio coger un lapsus de 2 horas y dedicarlo a la conciliación, pero esas 2 horas no hay nadie que te haga el trabajo a ti. Ese trabajo te está esperando [P9: mayo 2007].

Incluso, cuando los PDI se toman una reducción de jornada, que corresponde a un $30 \%$ del horario laboral, y por ende de la carga laboral (aunque no siempre es así), los PDI se comparan con lo sencillo que sería conciliar, según su perspectiva, para el PAS:

(...) cuando eres administrativo, por ejemplo sí que es real del 30\%. (...) Estás el 30\% de horas menos en la Autónoma y punto. Y para cualquier PAS, pero para el profesorado no es real [P10: mayo 2007].

También y muy marcadamente suelen compararse con su pareja. Se negocia quién será el usuario de las políticas, aunque de una forma implícita muchas veces, y esto se refleja claramente en quién es quien toma el recurso.

(...) el permiso de las 16 semanas es algo que hablas pero bueno, en nuestro caso, todavía entiendo que la madre siempre es... creo que está bien que lo haga ella, porque si tienes que dar el pecho, este tipo de cosas creo que es más adecuado o más fácil que hagas medio el padre medio la madre, por un tema de necesidad física de las criaturas. Entonces es algo que con los niños lo dábamos por supuesto. Era mi mujer la que iba a pedir el permiso las 16 semanas. (...) Ella este año tiene jornada reducida (...) entonces, durante el primer año les dejan hacer un horario reducido y trabaja de 9 am a 2 pm.(...) yo jamás me planteé tomar un permiso de paternidad (...) es un tema que no discutimos. Lo veíamos como natural, obvio, no sé cómo decirlo. El rol tradicional, el rol de toda la vida que es la mujer la que... y no nos lo planteamos [P7: mayo 2007].

Para introducir al análisis la perspectiva de género y dentro de ésta, el concepto de sexismo benevolente, expondremos algunos casos. El período de baja maternal puede evidenciar los marcados roles en la familia. Los mismos actores ven una distinción:

Ella se ha ocupado mucho de los hijos, yo también, pero no tanto como ella. He procurado ayudar en lo posible, porque yo me he encontrado con colegas que han tenido problemas familiares precisamente por la profesión [P8: mayo 2007]. 
"Ayudar en lo posible" es una frase muy concurrida. En general esta actitud del varón hacia la mujer de "ella es la que se encarga de eso y yo sólo la ayudo" refleja el sexismo benevolente. Un tipo de sexismo encubierto y casi invisible. Sin embargo, éste también puede manifestarse de mujer hacia hombre:

pero mi marido está ahora en una temporada de mucho trabajo. A él le ha tocado llevar un cargo de estos institucionales, y obviamente requiere de más atención, por tanto yo soy un poco la que hago esa conciliación laboral en mi casa [P3: mayo 2007].

A la vez, esta actriz (que es un actor, pero intencionalmente expuesto aquí con distinción de género) acepta implícitamente que es él quien debe trabajar más y ella debe facilitarle ese tiempo y evitar que sea él quien haga las tareas doméstico-familiares. A veces, es bastante difícil de evidenciar, en especial cuando se trata de aludir que cada quién hace las tareas domésticas que mejor sabe hacer. ¿Qué tarea doméstica sabe hacer el varón? ¿No las sabe hacer porque no es hábil, porque no se las han enseñado o porque no quiere darse el tiempo para hacerlas?

(...) yo tenía un horario flexible entonces yo hacía las cosas de casa. Él hacía otras cosas como cambiar las ruedas pinchadas y cosas de estas [risas]. Las cosas eléctricas, arreglarlas si hacía falta. Cosas como estas que yo no sé. Cada uno hace lo que mejor sabe [P6: mayo 2007].

En cambio otros, probablemente una minoría, traducen las políticas como una cosa aprovechable, sea el usuario hombre o mujer:

en todo caso si tienes posibilidades de tener alguna ayuda por parte de la empresa, como esos períodos, vale la pena cogernos. (...) Ya que teníamos la posibilidad de pedir el permiso, aprovechamos al menos, pues el impacto estaría más amortiguado [P9: mayo 2007].

(...) entendimos que teníamos que compartir la responsabilidad entre los dos. Es decir, los dos somos padres del hijo, hay unas cosas que sólo puede hacer la mujer, pero hay otras que pueden cargarse al hombre. Es decir, si yo tengo una reducción de jornada, puedo encargarme de llevar al hijo a la guardería o de recogerlo o de atenderlo si está enfermo. Lo que no puedo hacer es darle el pecho (...) pero puedo encargarme yo sólo si dispongo del tiempo para hacerlo [P10: mayo 2007].

Esta última frase requiere que nos detengamos en ella unos momentos. Él puede encargarse si dispone del tiempo. ¿Y ella tiene tiempo? ¿Son las políticas un instrumento suficiente para fabricar ese tiempo? ¿O se ha entrenado una habilidad especial para vivir en una doble presencia? La doble presencia, término acuñado por la socióloga italiana Laura Balbo (1978), es un concepto que parece definir mejor lo hasta ahora entendido como doble jornada. Algunas personas llevan todo en la cabeza en un mismo espacio y tiempo el conjunto de la carga total de trabajo que deben realizar cotidianamente, los hombres de una forma diacrónica y las mujeres, sincrónicamente.

Tanto las mujeres como los hombres son estereotipados, esto se refleja en los diferentes roles que se les adjudican a cada sexo, los llamados roles de género. La diferencia entre los estereotipos hacia los sexos es que para los hombres éstos van unidos a un beneficio y para las mujeres a un perjuicio. El sexismo ambivalente constituye un constructo bidimensional que abarca dos tipos de actitudes sexistas: hostil y benevolente. Así, el elemento hostil (SH) comparte con el sexismo más tradicional su carga afectiva negativa y se define como un prejuicio hacia las mujeres que las considera en una situación de inferioridad con respecto a los hombres, y la valoración negativa hacia los hombres como ostentadores del poder y responsables de la relegación de la mujer a un estatus inferior. El sexismo benevolente (SB) se expone con un tono afectivo positivo, por un lado idealizando los roles tradicionales de las mujeres, al mismo tiempo que se enfatiza su debilidad y necesidad de protección, reforzando 
hacia los hombres su papel protector complementario. El sexismo hostil y benevolente representan, por tanto, una potente combinación para mantener la subordinación de la mujer, actuando como un sistema articulado de castigos para que las mujeres sepan "cuál es su sitio" (sexismo hostil) y de recompensas (sexismo benevolente).

De hecho, el SB puede ser incluso más perjudicial que el hostil, pues puede utilizarse para compensar o legitimar el SH y, dado que el sexista hostil no suele considerarse a sí mismo sexista, la intervención en contra de esta forma de sexismo puede presentar dificultades añadidas. La hostilidad sola crearía resentimiento y rebelión por parte de las mujeres, y los hombres no desean ganarse la antipatía de las mujeres, dado que dependen de ellas. El sexismo benévolo debilita la resistencia de las mujeres ante el patriarcado, ofreciéndoles las recompensas de protección, idealización y afecto para aquellas mujeres que acepten sus roles tradicionales y satisfagan las necesidades de los hombres. Exponemos un caso de actitud benevolente, esta vez de la mujer hacia el hombre:

[buscar a los niños] me lo combino con mi marido, pero mi marido está ahora en una temporada de mucho trabajo. A él le ha tocado llevar un cargo de estos institucionales, y obviamente requiere de más atención, por tanto yo soy un poco la que hago esa conciliación laboral en mi casa. (...) ese papel que te digo que he un poco asumido yo, en cierta manera, quieras que no, también lo aparto. Pero es una persona que ayuda mucho y colabora mucho. Quiero decir, no tendría ningún problema... Mi marido es una persona que ayuda bastante [P3: mayo 2007].

Ella concuerda implícitamente, que debe colaborar con su marido y facilitarle el tiempo. Por esto, ella se sobrecarga y acaba frustrada:

Hubo una semana que estuve yo mala, pero lo más normal es que como están los virus por ahí, alguno más [de casa] caiga. Y efectivamente cayó mi hijo pequeño de 3 años malo. Y entonces, mi semana más la semana del niño... pufff. Con perdón, unos enfados y unos cabreos llevaba. Hasta mi marido dice: "no P3, que me vengo, que yo salgo de la reunión a las 12:30 y me vengo a la 1pm y tal". "Si para qué? iqué hago yo en dos horas?". A mí dos horas, contesto los e-mails, pero ya los hago desde casa, y estaba enfadada. Mi sentimiento era de frustración o un enfado, no lo sé exactamente [P3: mayo 2007].

Pero ser sexista, aunque sea de manera muy encubierta, es algo heredado social y culturalmente. Así se nos enseña a entender el mundo desde pequeños:

¿Cómo lo hago [las tareas domésticas]? A ver, primero es un tema que me gusta. Mi educación un poco me lo ha puesto. La educación que yo he recibido, por lo que he visto con mi madre. Mi madre era igual que yo, ella no era una ama de casa exclusiva. Era profesora, trabajaba mucho y realmente a mi madre la vi poco. La vi poco en casa. Muchas veces yo era más pequeña y era yo la que hacía la comida [P3: mayo 2007].

En muchas ocasiones, las tareas simples o más mecánicas las suele hacer el hombre, el resto, la mujer, y las más duras y sucias... y si se puede... imejor contratar a alguien! Notemos el orgullo con que ellos cuentan sus hazañas en el hogar:

(...) en la última época de su cáncer [de mi suegro] ella estuvo muy pendiente de aquello y entonces fue cuando yo aprendí a planchar por ejemplo [risas]. (...) Sí, porque antes lo tenía que hacer ella y entonces vi que le suponía 2 o 3 horas más de libertad por semana, bueno, entonces con mucho gusto empecé a esto, y ahora si hay un fin de semana me quedo... que no sé que hacer. (...) Lavar la ropa, es ella, porque es ella quien sabe cómo funciona la máquina y siempre la ha controlado ella y la parte de plancha hace ya unos 10 o 12 años esto lo hago yo, por ejemplo [P8: mayo 2007]. 
A este último participante se le preguntó en la misma entrevista lo siguiente: ¿Ud. siente que hay roles bien marcados en su familia? Y su respuesta fue "Sí, en cierta manera sî". En la cita anterior, podemos notar que el planchado comenzó siendo un "favor", para que la mujer dispusiera de un par de horas más para visitar a su padre enfermo. Luego el marido mantuvo la costumbre del planchado y lo lleva haciendo muchos años. Sin embargo, la clave está en que él eligió planchar y que nadie lo obligó a hacerlo.

\section{Retorno a la actividad académica: des-domesticación y re-domesticación.}

Los PDI saben que al acogerse a los recursos de conciliación hay que dejar entrar los cambios que este cambio en la rutina supone, esto es, un ajuste material previo para dejar ir estos recursos y volver a la normalidad, lo que se llama proceso de des-domesticación. El proceso de des-domesticación o despojo se inicia cuando el usuario pierde interés en el artefacto porque está gastado o lo quiere reemplazar.

Las actividades académicas e investigativas se retoman con cautela. Paulatinamente ellas logran volver a tener sus vidas, con algunas limitaciones en varios ámbitos; personal y laboral:

(...) a mí este horario [el de la guardería], si uno aprovecha bien esas horas, son horas más que suficientes para trabajar mucho. Y bueno, retomé casi con la misma intensidad... nunca se toma con la misma intensidad, pero retomé bien la vida laboral [P4: mayo 2007].

Se desarrolla una cierta habilidad para complementar el proceso de des-domesticación a las políticas. Una vez que la persona ha vuelto al puesto de trabajo se organiza minuciosamente para ser lo más eficiente posible en la administración del tiempo: "Ya seleccioné un pediatra que tenía horarios-mañana y horarios-tarde, (...) Intento pedir horas de estas de tarde, si no es cosa de urgencia" [P3: mayo 2007].

Esta incesante búsqueda por la administración eficiente del tiempo, que pareciera ser una constante en los participantes, tiene distintas maneras de manifestarse. Las personas se las han de apañar de cualquier forma con tal de conseguir sus preciados minutos, pagándole a alguien o negociando turnos.

Como se ha mencionado al principio del artículo, el proceso de re-domesticación es aquél donde los usuarios aprenden nuevamente a usar viejas tecnologías para nuevas situaciones o contextos. En este caso, es una mejora al permiso por maternidad. Se llama reducción de jornada comprimida que corresponde a 12 semanas laborales y puede tomarse luego de las 16 semanas de permiso, sumando así 28 semanas.

Sí, pero entonces no pude tomarme más que las 16 semanas de baja, porque me parece que no estaba la ley esta [P3: mayo 2007].

Le pedimos a la participante que hiciera el ejercicio y pensara cómo actuaría si hipotéticamente quedara embarazada, para poder percibir su proceso de des-domesticación inicial del trabajo, y a la vez, su proceso de re-domesticación ante el nuevo recurso:

Me acogería a las 12 semanas laborables y si fuera mayo, pues sería mayo, junio... febrero. Sí. Lo tendría para febrero, sería perfecto, porque empieza el segundo semestre y ya no daría clases, por tanto luego las 12 semanas. 16 semanas... casi-casi acabaría el curso. Luego me iría las 12 semanas y empezaría en septiembre del año siguiente. Tendría que dejar mi puesto de Coordinadora de promoción de las relaciones externas de la Facultad que es un dinero que gano extra, claro, tendía que dejarlo y pasarlo a alguien, a algún conocido y así decírselo al decano, que yo lo dejo [P3: mayo 2007]. 
Es importante para el PDI sentir el apoyo de sus compañeros. Ellos son vistos como nuevos aliados que se movilizan en pos de los intereses del PDI padre/madre. Si hay un caso de emergencia y este PDI debe ausentarse inmediatamente, puede contar con la ayuda de un compañero.

Aquí, si se encuentra mal [el niño], pero no es nada importante, puedo venir aquí y cerrar lo que estuviera haciendo, buscar un compañero que me dé la clase o que haga lo que yo esté haciendo, mientras lo tengo a él (...) lo puedo gestionar todo [desde] aquí. Es muchísimo más cómodo [P10: mayo 2007].

Ahora los PDI están de regreso en el puesto de trabajo. Pero para que se sientan tranquilos y seguros, ha de haber pasado por un período muy difícil. Debieron informarse y tomar una decisión con respecto al lugar donde cuidarían del niño desde que ella retome las actividades laborales hasta que el bebé entre al colegio, a los 3 años.

\section{Conclusiones}

En este trabajo hemos planteado una óptica distinta para ver las políticas de conciliación como una tecnología que es apropiada y domesticada cotidianamente por los usuarios. Esta perspectiva enriquece el entendimiento que tenemos de las condiciones laborales y normas institucionales, en cuanto que cada PDI pasa por procesos de ajuste material y emocional, domesticación y traducción, que son procesos para nada lineales, sino que muchas veces se dan simultáneamente.

En el futuro, cada vez que los PDI se acojan a estos recursos, que se transforman en políticas domesticadas e integradas rutinariamente a la vida cotidiana, tendrán lugar modos de actuar, que serán cada vez más fluidos y pronto podrá "personalizarlos", y las políticas tendrán la agencia de modificar su manera de relacionarse con el mundo, en especial, su familia y tiempo libre. Así, la acción es distribuida, según argumenta ANT: entre humanos y nohumanos. Es decir, entre las políticas y el PDI, sus valores, su familia, etc. considerando muchos actantes difícilmente percibibles.

Los procesos de domesticación de las tecnologías o artefactos técnicos, nos pueden abrir paso a conocer los cambios sociales o las estabilidades. Los procesos de domesticación de las políticas de conciliación varían notablemente dependiendo del recurso que esté en uso, o la configuración que le dé la persona. No olvidando que este es un proceso, a la vez, recíproco, pues las políticas configuran el usuario y viceversa. Los PDI se adecuan a las condiciones que propone el recurso, y al mismo tiempo son ellos quienes adaptan el recurso a su vida diaria, a su rutina laboral y a su familia. El proceso de domesticación depende tanto de la persona que se apropia a la tecnología, como a otros procesos de domesticación terminados, de otras tecnologías que afectan el equilibrio trabajo y familia. Existen tecnologías alternativas que se domestican a la vez que usamos los instrumentos de conciliación, incluso, podríamos prescindir de ellos. Estos mecanismos alternativos o complementarios son: el horario flexible, rango jerárquico que proporciona poder de decisión en el puesto de trabajo, el "toreo" con los hijos en manos de distintas personas o instituciones, la ayuda de los propios hijos (aunque no sea mucha), entre otros.

¿Por qué nos cuesta tanto? ¿Conciliar es un coste? Definitivamente los recursos que se ofrecen en la UAB ayudan económicamente a mantener la familia. Lo cual no significa que este tipo de recursos promuevan la natalidad entre los PDI:

Es una reducción muy pequeña. Era útil, lo que pasa es que tampoco te soluciona la vida, pero te 
ayuda [P10: mayo 2007].

[Gespa] es el único mecanismo que tenemos de conciliación de la vida laboral y familiar en estos momentos, que funcione desde hace tiempo y que esté contrastado. Porque lo demás son políticas sobre el papel, son planes aprobados por un comité o por un concejo, por un claustro, muy bonitos sobre el papel, pero luego cuando hay que ponerlos en práctica es otra cosa [P4: mayo 2007].

Para dar cuenta de los procesos de traducción entre lo que las políticas dicen y lo que entiende y hace el PDI, la forma en que se llevan a cabo los procesos de domesticación nos dirán qué variables influyen fuertemente en la traducción de las políticas por los PDI. En este sentido, pareciera existir efectos inesperados en la aplicación de los recursos: sexismo y jerarquía son los obstaculizadores más decisorios en la conciliación.

Vimos los procesos de ajuste material y emocional, des-domesticación y redomesticación y observamos cómo estos procesos se ven condicionados por el sexo del usuario. Pareciera ser que las políticas o programas ofrecidos generan un abanico enorme de posibilidades de domesticación del recurso. Sin embargo, este rango de alternativas es reducido debido a dos factores, principalmente; el sexismo y el rango jerárquico. El primero, el "sexismo", es un concepto con una connotación negativa, pero ampliamente internalizado en los PDI, y supone que ellos estereotipan los roles que juega un PDI hombre y una PDI mujer en la sociedad. Estos roles no son iguales. Esto mismo hace que sea "mejor visto" (aunque no es lo deseable) que la mujer sea quien se tome los permisos y definitivamente "mal visto" que lo hagan los hombres. Incluso, las tareas doméstico-familiares también suelen organizarse según este mismo criterio: "(...) yo tenía un horario flexible entonces yo hacía las cosas de casa. (...) Cada uno hace lo que mejor sabe" [P6: mayo 2007].

¿Será que cada uno hace mejor lo que le enseñan a hacer según pautas sexistas? ¿Es esta una estabilización camuflada de la división sexual del trabajo? Si bien las políticas de conciliación nacieron para apoyar a la mujer y hacerles cómoda la maternidad, con el fin de no perder el trabajo, hoy en día, estas declaraciones intentan permear un espíritu de igualdad de género. En las Disposición Adicional Primera, del Convenio Colectivo para el personal docente e investigador de las universidades públicas catalanas, se hace referencia a la política de género que aplicará la UAB y demás 6 universidades firmantes, aludiendo a favorecer la igualdad de género de las siguientes formas: 1) priorizando el acceso a la mujer a todos aquellos ámbitos y órganos donde actualmente su presencia sea deficitaria; 2) impulso de políticas de acción en la selección del PDI laboral y de soporte a la carrera académica de las mujeres; y 3) los sindicatos firmantes desarrollarán medidas para favorecer la paridad de género en los órganos de representación colectiva del PDI laboral. Para el caso de los permisos y licencias contenidos en el Título 7 de este convenio colectivo, no se hace distinción alguna en el sexo del usuario. En este título, recién se menciona la distinción "trabajador o trabajadora" en el apartado j) del artículo 37 relacionado con el permiso de lactancia. La distinción viene a confirmar que esta herramienta de conciliación está disponible para todo PDI, sea hombre o mujer. ¿Pero qué hace que el permiso de lactancia sea sólo tomado por la madre? A pesar de que el convenio habla de "personas" sin distinción de sexo, pareciera haber una lectura única. Se podría creer que es por un tema biológico. Pero, es necesario considerar que hay muchas mujeres en el mundo que no pueden dar el pecho, por ejemplo, porque sus hijos son alérgicos a la leche materna. En esos casos, se debe alimentar a través de un suplemento lácteo en un biberón. Ahora la mujer no sería la única que podría alimentar a su bebé recién nacido. Aún así, en este caso, ipor qué el padre no se toma el permiso de lactancia? En resumen, el primer factor de reducción de la amplitud de movimiento en cuanto a tomar recursos conciliadores es el sexismo. Este lo reduce tanto para hombres como para mujeres, siendo aún más amplio para las mujeres, sin duda, influenciado por el sexismo benevolente y protector hacia la mujer.

De la amplia gama de opciones de domesticación de los recursos de conciliación, el segundo factor o estrategia de traducción que reduce el movimiento del PDI es el "rango 
jerárquico". Pareciera ser que quienes están en un puesto de catedrático o de titular pueden aprovechar mejor los instrumentos de conciliación, e incluso, el equilibrio mismo, sin hacer uso de los recursos que se ofrecen. Esto porque aquellos que no tienen un puesto estable buscan incesablemente la estabilidad laboral, la superación de la precariedad de sueldo, o dejar los intensos esfuerzos por promocionar a una plaza más alta. Muchos de aquellos que aún viven en esta situación, postergan la familia o simplemente, no concilian, es decir, no equilibran el tiempo que le destinan a la familia y al trabajo, pues hay una presión económica significativa. Hay quienes sacrifican horas de descanso, viajes por el trabajo, para lograr el ansiado equilibrio:

(...) creo que los demás a lo mejor acabarán cobrando menos o igual que nosotros, pero que tendrán igual o más problemas económicos y encima no ven a su familia. Entonces esto para mí es una suerte, aunque sea a costa de dormir menos, y de ir cansado, pero poder estar cuando se bañan los niños, poder estar en la cena, poder salir a jugar por la tarde con ellos. Y bueno, si eso implica que duermo menos esta noche, bueno. ¿Qué le voy a hacer, no? [P7: mayo 2007].

(...) he tenido que renunciar a una serie de viajes que hubiera podido hacer y entonces he dado importancia a la vida familiar [P8: mayo 2007].

Ante la pregunta, si tuviera Ud. que pedirle algo a la Autónoma, en temas de conciliación, qué política o qué programa se le ocurre que podría hacerle a Ud. más fácil la vida familiar, se contestó:

La solución sería que nos pagasen el doble, entonces podrías hacer menos cosas, tendrías que hacer menos cosas para complementar tu salario. (...) el problema que veo es que tengo que trabajar mucho, pero es por un tema económico, sencillamente. (...) Claro, si cobrase el doble pues a lo mejor entonces no tendría que estar coordinando programas, que ya te lo piden también, pero bueno, ya lo haces porque quieres. A lo mejor no tendría que dar tantas clases en másters, no tendría que hacer convenios de colaboración con empresas, podría prescindir más de ello. Por eso te digo, pero es más básico el tema, es más sencillo. En mi caso [P7: mayo 2007].

Esas citas son pronunciadas por participantes hombres. Al igual que las citas que hacen alusión al descanso y los congresos; la familia también supone un sacrificio para la trayectoria profesional. Curiosamente, para las mujeres, pareciera no considerarse el impedimento económico tanto como los hombres:

(...) sé que hay un sacrificio, pero no me importaría. Una marcha atrás, otra vez marcha atrás.

(...) laboralmente se pierde, yo pierdo [P3: mayo 2007].

[ha habido un par de casos que] Lo han tenido que dejar porque no les salía a cuenta. Primero porque no disfrutaban de sus hijos, y segundo porque trabajaban para que disfrutaran otros [risas], de los que no son sus hijos. Entonces, realmente, aunque cueste decirlo pero ella ha sacrificado el trabajo y no el padre [P3: mayo 2007].

Un sueldo menos en casa podría costearlo la pareja, con mucho esfuerzo, pero también hay una variable muy importante que actúa como obstaculizador de la conciliación; que nos guste trabajar y que deseemos realizarnos profesionalmente. No es nada de extraño. Ellas y ellos quieren eso. ¿Quién lo logra? Esa es la pregunta. Quizás, para una mujer la realización personal pesa más que la realización profesional. ¿O es que se lo han puesto difícil? ¿Quién decide?

A partir del Convenio Colectivo y del Estatuto del Trabajador Público, estas políticas de flexibilización horaria familiarmente responsables son herramientas que tienen dos grandes objetivos, facilitar la fabricación de tiempo extra para destinarlo al cuidado familiar y esto, si es posible, que sea percibido a la vez como una política promotora de igualdad.

Con el fin de complementar este mismo estudio, de manera de crear una prospectiva, sería de utilidad entrar a las mesas paritarias para ver el proceso de negociación del convenio 
colectivo y analizar los procesos de traducción en uno de los nodos principales. Además, sería interesante conocer las distintas tecnologías alternativas que domestican personas que no hacen usos de los recursos de conciliación trabajo y familia en la UAB. De esta misma manera, el presente trabajo puede ser contrastado con los procesos de domesticación y las estrategias de traducción que lleva a cabo el personal administrativo y de servicios (PAS).

Sin embargo, a partir del recorrido que hemos hecho en los procesos de domesticación de estas políticas, podemos concluir que la forma en que se llevan a cabo los procesos de domesticación reflejan qué variables influyen fuertemente en la traducción de las políticas por los PDI. Las actitudes sexistas y la posición jerárquica en la organización, dos aspectos culturales de la UAB, intervienen en la forma de domesticar las políticas, tanto para mujeres como para hombres.

\section{Agradecimentos}

Este trabajo fue apoyado por la Fundación Carolina y la Universidad del Desarrollo. Los autores agradecen a los participantes entrevistados su colaboración y confianza en este proyecto. Katherina Kuschel agradece especialmente la orientación, estímulos, críticas, y sugerencias al Dr. Francisco Tirado y a Consuelo León.

\section{Referencias}

Balbo, L. (1978). La doppia presenza. Inchiesta, 32, 3-6.

Callon, M. (1986). Some elements of a sociology of translation: domestication of the scallops and the fishermen of St. Brieuc Bay. En J. Law (Org.), Power, action and belief: a new sociology of knowledge. London: Routledge $\&$ Kegan Paul.

Callon, M. (1987). Society in the making: the study of technology as a tool for sociological analysis. En W. E. Bijker, T. P. Hughes, and T. J. Pinch (Orgs.), The social construction of technological systems. Cambridge: MIT.

Chinchilla, N., Poelmans, S. \& León, C. (2003). Políticas de conciliación trabajo-familia en 150 empresas españolas. IESE Business School, Documento de investigación 498.

Glick, P. \& Fiske, S. T. (1996). The Ambivalent Sexism Inventory: differentiating hostile and benevolen sexism. Journal of Personality and Social Psychology, 70, 491-512.

Grint, K. \& Woolgar, S. (1997). The machine at work. Technology, work and organisation. Cambridge: Polity.

Hine, C. (2000). Etnografía virtual. Barcelona: UOC.

Latour, B. (1984). The pasteurization of France. Cambridge and London: Harvard University.

Latour, B. (2002). Morality and technology: the end of the means. Theory, Culture $\mathcal{B}$ Society, 19 (5/6), 247-260.

Latour, B. (2005). Reassembling the social: an introduction to actor-network-theory. Oxford: Oxford University.

Lefebvre, H. (1971). Everyday life in the modern world. New York: Harper and Row.

Ley 39/1999, de 5 de noviembre, para promover la conciliación de la vida familiar y laboral de las personas trabajadoras. Boletín Oficial Español.

Ley Orgánica 3/2007, de 22 de marzo, para la igualdad efectiva de mujeres y hombres. Boletín Oficial Español.

Lie, M. \& Sorensen, K. (Orgs.) (1996). Making technology our own? Domesticating technology into everyday life. Oslo: Scandinavian University.

Resolución TRE/309/2006 (2007). Diari Oficial de la Generalitat de Catalunya. 
Vitores, A. (2001). Recensión de F. Domènech y F. Tirado: Sociología simétrica. Athenea Digital, 1 (0). Barcelona: Gedisa.

Winance, M. (2006). Trying out the wheelchair: the mutual shaping of people and devices through adjustment. Science Technology \& Human Values, 31 (1), 52-72.

\section{Endereço para correspondência}

kathykuschel@gmail.com, lupicinio.iniguez@uab.es

Recebido em: 30/11/2007

Revisado em: 13/03/2008

Aprovado em: 19/05/2008 